\title{
The influence of changes in the project on the reliability of heat power systems during construction and installation works
}

\author{
$T G$ Gorbunova $^{1}, T O$ Politova $^{2, *}$, Sh $G$ Ziganshin $^{2}, E V$ Izmailova $^{2}$ and $V V$ Serov $^{3}$ \\ ${ }^{1}$ The branch of LLC KER-engineering LLC Tatnipienergoprom \\ ${ }^{2}$ Kazan Power Engineering University, 420066, 51, Krasnoselskaya st., Kazan, Russia \\ ${ }^{3}$ JSC TAIF NK AZS chief power engineer Kazan, Russia
}

\begin{abstract}
However, during the construction and reconstruction of existing heat networks, cases that lead to unstable operation of newly laid or replaced areas arise. An important task is to minimize the reasons that can cause damage to replaced areas. Factors that negatively affect the reliability include: laying pipelines without design documentation, non-compliance of the regulatory requirements for their laying by installation organizations. The assumptions of design engineers developing the project and installers laying the heating main can lead to negative consequences, including a decrease in the reliability of the facilities functioning. Physical deterioration, coupled with the above factors, leads to a large number of failures of heat networks. Breakthroughs reduce the reliability of the entire heat supply system, worsen the quality of the supplied coolant and lead to an increase in the cost of maintenance of heat networks by operating organizations. The paper considers the influence of changes in the project during the construction and installation works on the reliability of the heat supply system.
\end{abstract}

\section{Introduction}

Almost all of the heat networks of Russian Federation were created during the period of mass housing construction of the 60-80s of the XX century. After 1991 there was almost no mass development, the volume of civil construction decreased sharply. Private construction companies almost did not build new heat networks. New residential buildings built after 1991 are mainly connected to old heat networks. The general condition of heat networks is estimated by experts as unfavorable. The reduction in funding led to a decrease in pipeline transpositions in the $90 \mathrm{~s}$ of the $\mathrm{XX}$ century. The management of heat supply enterprises, trying to prevent an increase in accident rate, tried to maintain the volume of pipeline reconstruction, reducing quality requirements and cheapening construction works. The restored networks had a very low resource and in 5-7 years required a new relocation. As a result, the number of emergency networks by 2000 began to grow exponentially. The number of accidents began to double every 2 years. On average they have increased several times over the past 6 years.

Physical deterioration of pipelines, together with the listed factors, leads to failure of heat networks. Emerging breakthroughs reduce the reliability of the entire heat supply system, worsen the quality of the supplied coolant, and lead to an economic rise in the cost of maintenance of heat networks by operating organizations. [1-3]
One example of the influence of design and construction and installation works quality on the functioning of heat networks is an accident at a transferred area in the Kukkovka village, Republic of Karelia, when about 50 thousand people were left without hot water. During the hydraulic tests, a rupture occurred on the feed pipe with a diameter of $500 \mathrm{~mm}$. The pipes changed their geometry under high pressure, as a result of which one of the concrete supports of the heating main was destroyed [4]. To avoid incidents like this, it is necessary to eliminate the negligence of construction and installation services and increase the technical and cultural level of specialists that are responsible for accepting working documentation for reconstruction or construction projects of new heat networks. When such examples arise, the concept of safe, reliable energy supply to consumers is called into question. Therefore, the preservation of the principle of no-failure, safety and reliability of heat networks should be at all stages of their life cycle.

The photo (figure1, figure2.) presents photographs showing the intersection of heat pipelines by other communications, which contradicts the requirements of regulatory documents during laying heat networks in a non-channel way.

Laying areas of the heating main with polyurethane foam insulation is carried out with gross violations of technological norms and rules. The service life of such a pipeline will be insignificant. A rupture of the pipeline will lead to erosion of the soil and leakage of the coolant to large areas. High coolant temperature can lead to

Corresponding author: politovatatyana@ya.ru 

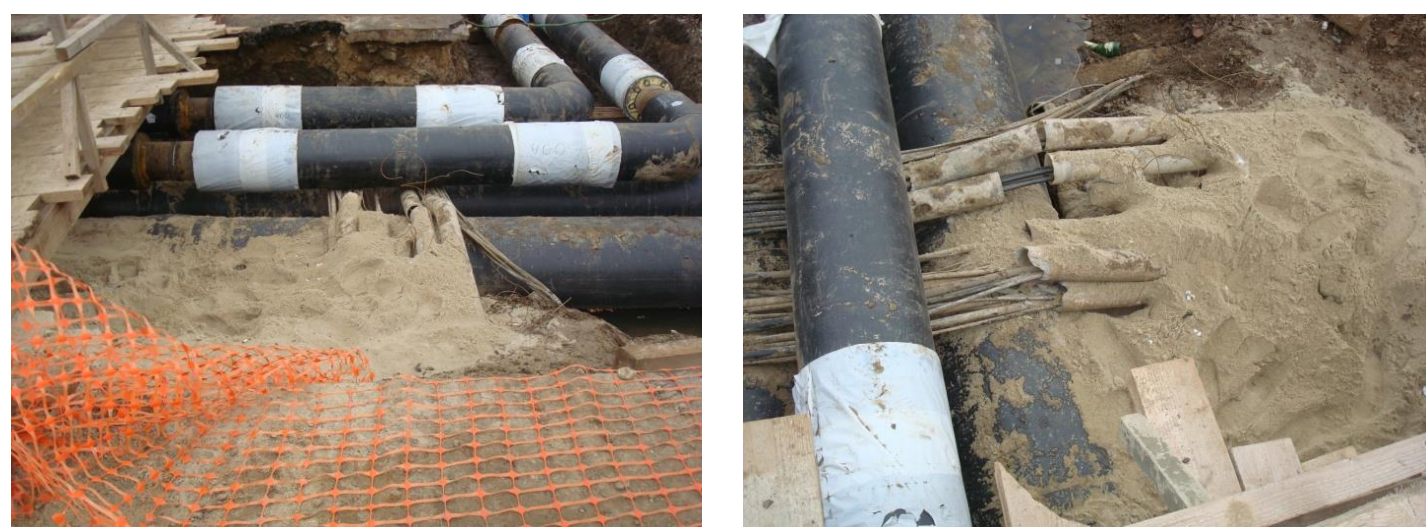

Fig. 1. The intersection of heat pipelines by other communications.
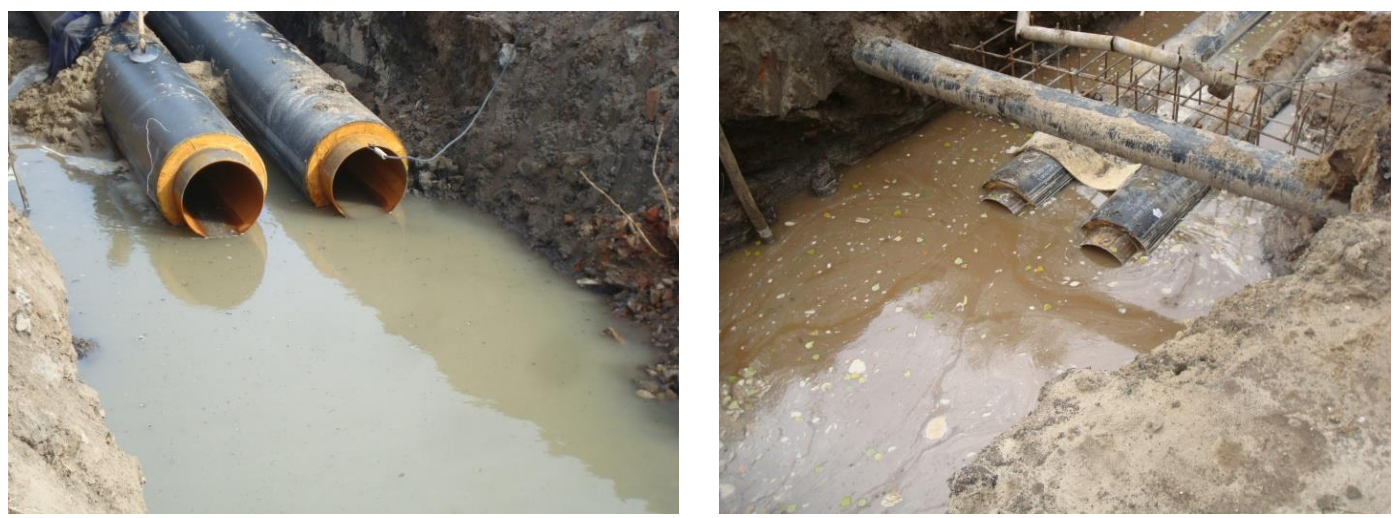

Fig. 2. Laying heat networks in a non-channel way with a violation of technology.

burns, or to more serious consequences, as happens in some cities $[5,6]$.

The heat networks included in the energy complex of the country have an extremely complicated topological structure. Nowadays, most heat supply organizations operate as a large emergency service. They consider this the norm and are no longer able to change anything on their own, as they are in conditions of constant underfunding. The deterioration of the situation is expected after the widespread installation of metering devices in residential buildings and budgetary institutions, since the heat supply organizations will cover the actual losses in the networks, partially transferred today to consumers [7].

\section{Methods}

Author's supervision - control by the authors of the project, the design organization for the compliance of the created, under construction object with design decisions adopted during the design and recorded in the documentation. According to the results of author's supervision, most design organizations are faced with partial or comprehensive discrepancies in the completed construction and installation works of design documentation. It negatively affects the planned reliability of the system.

Often during the construction of a heating main in accordance with the project, the construction organization has situations that require changes to the project. This happens for various reasons, as examples are the following:

- when opening the ground, power cables were discovered that were not marked on the topographic survey (figure 3), which led to a change in the design;

- in order to accelerate the construction, the installation organization proposed to cancel included in the project dismantling of the intersected heating main in the channel and bypass the existing heating main in the channel, etc.

Obviously, any change in the project entails an increase in the cost of construction and design works and a decrease in the reliability of the heat supply system as a whole. The increase in the cost is explained by the fact that almost any change in the project leads to the appearance of new parts that were not previously included in the specification, as well as to the forced downtime of the equipment until the final decision is made. In the case of changes, it will be the waiting for the changed design documentation. In turn, the appearance of new parts in the project entails an increase in the number of joints, and, consequently, welds (figure 4).

It is known that welded junctions (for example, during welding pipeline elements - joints) are among the most stressed areas of the structure. At installation of turns of a heating main, solders, branches, inserts of fittings, etc. (figure4) the use of cutting pipe pieces can negatively affect the quality of the cut processing and 

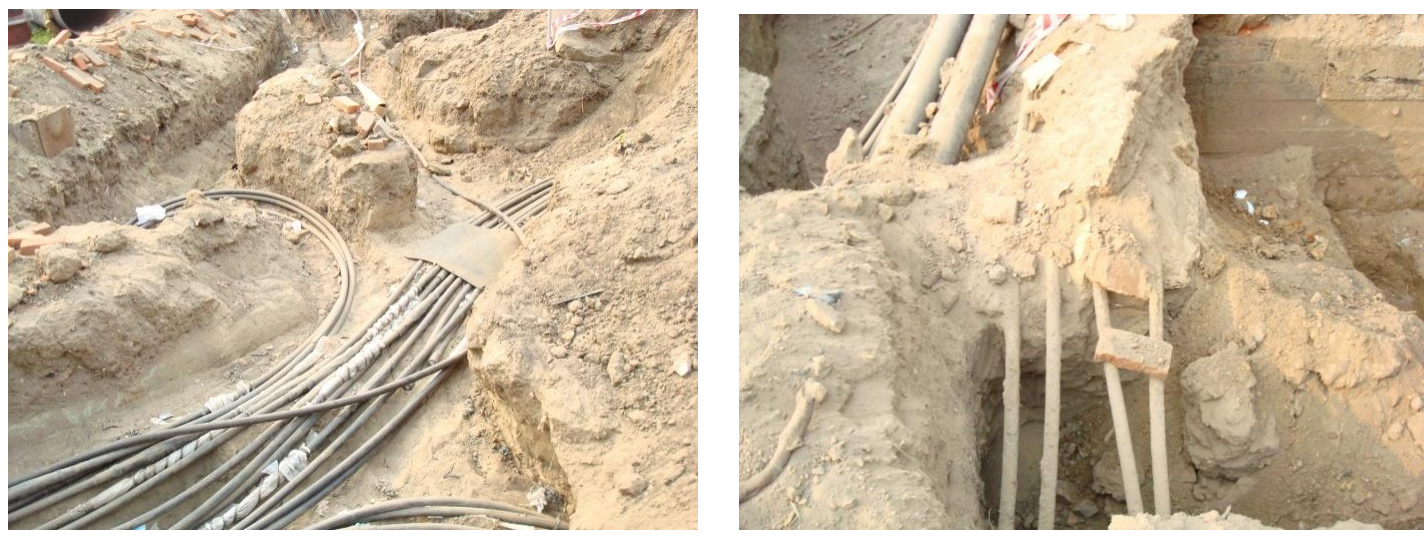

Fig. 3. Detected power cables not marked on topographic survey.

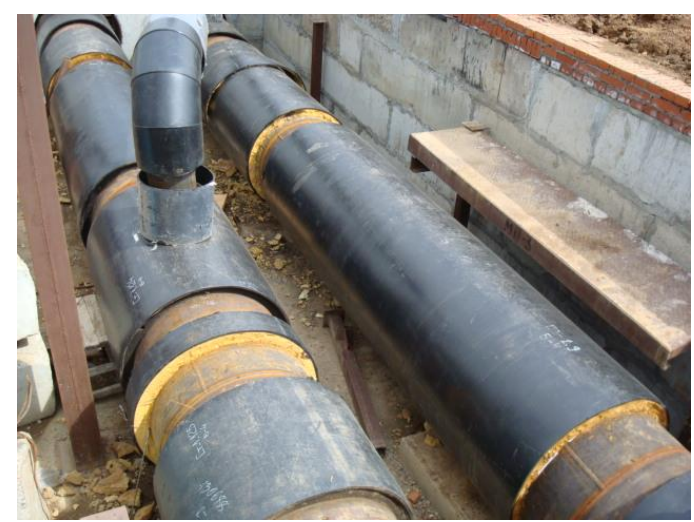

Fig. 4. The use of cutting pieces of pipe on one of the pipelines.

provoke improper installation of heat-shrinkable couplings. According to All-union State Standard, the length of the pipe supplied from the manufacturer is 10 or $12 \mathrm{~m}$.

Thus, there is a question: "How do changes in the design affect the reliability of the designed heat pipeline?".

\section{Results}

One of the ways to solve the improving the efficiency of heat supply is the transition to the creation of a monitoring and diagnostic system with the subsequent formation of a system for the major repairs of heating networks. The basis of this system is the automated control of the pipelines and technical equipment state.

Analysis of methods for determining the state of heating networks showed two main directions for solving the problem:

1. Carrying out the control of heat pipelines by instrumental methods.

2. Prediction of damage and assessment of the reliability of heating networks based on statistical methods.

Detection of leaks from pipelines is a difficult technical problem, the solution of which requires special equipment. The main control methods are: acoustic, correlation, thermal.

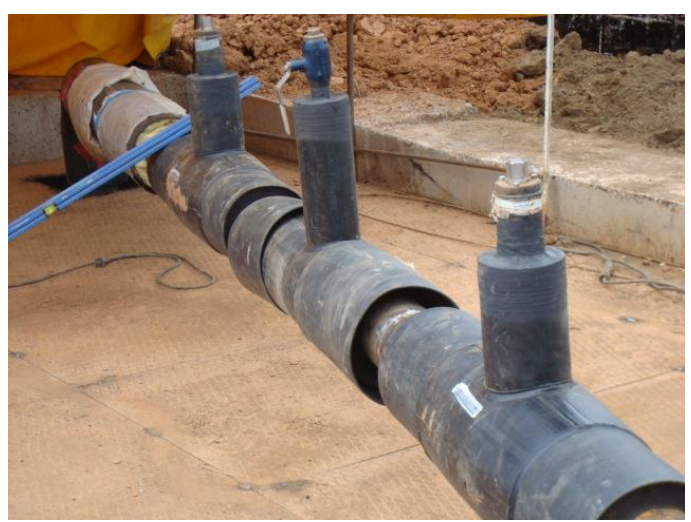

An integrated approach to solving the problem of detecting water leaks from a pipeline using instruments significantly increases the accuracy of detection of an emergency site. At the same time, the use of diagnostic methods determining the condition of the pipeline should help identify potentially dangerous hydrogeological areas. It would justify the need for additional waterproofing, drainage, insulation of channel overlaps, and the possibility of developing ways to efficiently ventilate them to dry insulation plating and prevent condensate from falling out.

However, in the conditions of market economy it is important to provide a feasibility study on the efficiency of the heating networks reconstruction, because the final result is investment in the construction of the facility and, as a consequence, operating costs. There is a need to determine not only the reliability of the system, but also the effectiveness of the system.

The basis for ensuring the reliability of heating networks is the knowing of the real state of their elements. It ensures efficient use of resources for ensuring operability. Until recently, repair and relaying of heating networks were often carried out according to the service life and depreciation rate. However, the condition of heating networks elements depends on the specific conditions of their operation, which can both accelerate and slow down their destruction, which leads to satisfactory reliability of elements with high depreciation usage. 


\section{Results}

Nowadays, there are several basic approaches that allow in practice to assess the effectiveness of the implementation of diagnostic methods. Economic efficiency consists of direct and indirect saving. Direct saving can be attributed to reduced equipment repair costs, an increase the real turnaround time due to the exclusion of scheduled repairs. In addition, it also reduces the cost of repair by identifying defects, the elimination of which does not require dismantling. Indirect cost saving is due to lower costs that are not directly related to production costs (losses incurred as a result of unplanned downtime of equipment, release of defects, as well as the costs of eliminating accidents).

There is the cost of replacing $11 . \mathrm{m}$. pipeline in traditional insulation of different diameters in Table 1. During calculating the cost, the costs include restoration works (chernozem dumping, grass sowing, planting trees, restoring small architectural forms, etc.), cutting and adding soil during planning, as well as dismantling and paving works.

The reliability of the heat supply system as a whole depends on the reliability of its constituent elements, as well as on the way they are included in the system. Any pipeline system, excluding redundant branches, is a system of series-connected elements, which consists directly of the pipes themselves, as well as standard and non-standard parts laid down under the project (tees, bends, valves, etc.). Consequently, the probability of nofailure operation of a heat supply system consisting of the deadlock branches is:

$$
P_{C}(t)=P(t) \cdot P_{2}(t) \cdot \ldots \cdot P_{n}(t)=\prod_{i=1}^{n} P_{i}(t)
$$

where $\mathrm{n}$ - the number of elements (joints), which heat line branches consist of.

Figure 5 shows graphs of changes in the probability of no-failure operation of a series-connected system with identical elements depending on the number of elements $n$ for various values of the reliability indexes $P(t)$ of individual elements. As can be seen from the Figure5, the reliability of the system greatly depends on the number of elements in the system.

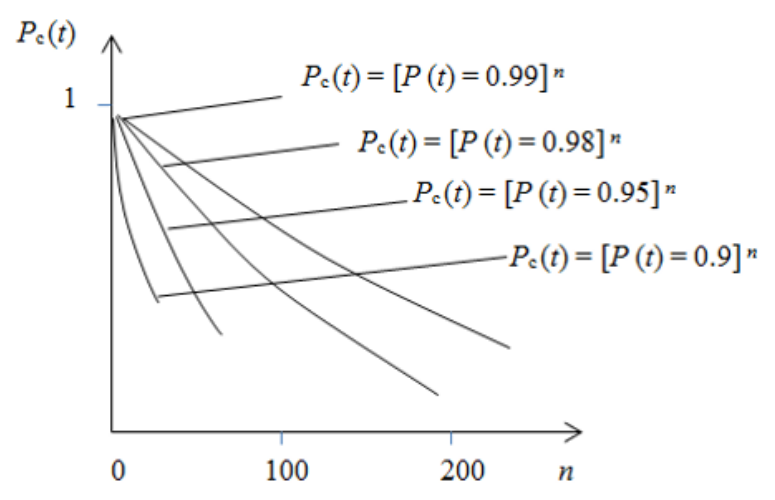

Fig. 5. Change in the reliability of the system depending on the reliability of elements and the number of elements $n$.
If we consider a branch of $1 \mathrm{~km}$ long (an area cut off by sectional valves), even during laying it only with pipes according to the lengths specified in All-union State Standards, with a pipe length of $10 \mathrm{~m}$, it is assumed that there are at least 100 joints (elements) in it, not counting bends, branches and fittings. During adjusting the project, the design engineer increasing the number of joints in the deadlock pipeline system, $1 \mathrm{~km}$ long, by 10 units, changes the reliability of the system as a whole, reducing the probability of its no-failure operation of the branch.

With an increase in the number of elements (element reliability is assumed to be 0.99 ) of such a pipeline system for every 10 units, the reliability of the system decreases by an average of $8-9 \%$ (Table 1 ). Consequently, the reliability of the designed area of the heating main before making changes to the design and after will differ significantly.

Table 1. The influence of the number of joints on the reliability of the system.

\begin{tabular}{|c|c|c|c|}
\hline The number of joints & $\mathbf{1 0 0}$ & $\mathbf{1 1 0}$ & $\mathbf{1 2 0}$ \\
\hline $\begin{array}{c}\text { The reliability of the system } \\
\text { (during the calculating the } \\
\text { initial reliability of the }\end{array}$ & 0.99 & 0.90 & 0.82 \\
system is assumed to be 0.99) & & & \\
\hline
\end{tabular}

\section{Conclusion}

1. In order to exclude difficult situations during construction (such as in the above examples), due to discrepancy of the provided source materials with actual data, it is important to provide the design department with up-to-date documentation (topographic maps, with geological research data printed on them, etc.) necessary for a better and more competent project creation.

2. It is recommended that design organizations, if possible, not to allow in the working documentation the presence of a large number of cutting pieces of pipes, especially at diameters of more than $200 \mathrm{~mm}$.

3. During coordinating the project with the customer and author's supervision, stipulate in advance the number of changes and limit the number of imposed new details for the case of possible adjustments.

\section{References}

1. Yu.V. Vankov, E.R. Bazukova, A.S. Gavrilov, Assessment of transport losses of heat at change of properties of thermal isolation, IOP Conf. Series: Earth and Environmental Science, 288 (2019)

2. E.R. Saifullin, Yu.V. Vankov, E.R. Bazukova, A. Maryashev, Evaluation of heat transporting losses due to changes of insulation properties during operation, IOP Conf. Series: Journal of Physics: Conf. Series, 1058 (2018)

3. Yu.N. Zvonareva, Yu.V. Vankov, Energy saving in systems of heat supply of the large municipal associations powered from several sources of heat, 
Bulletin of the Tomsk Polytechnic University, Geo Assets Engineering (2015)

4. The head of the Republic went to the emergency heating main. URL:http://izdat.karelia.ru/index.php?newsid=1683 Kukkovka

5. OJSC St. Petersburg Heating Grid will provide the necessary assistance to the family of a student of the Smolny Institute who died of burns. URL: http://www.rosteplo.ru/news.php?zag=1297149898

6. There were announced an emergency situation in three districts of Karelia. URL: http://www.flb.ru/info/14555.html

7. About improving the reliability and energy efficiency of heating networks. URL: http://www.vnipiep.ru/nadezhnost_teplovyih_setey. html

8. L.V. Chupin, V.I. Shlapakov, Analysis of the accident rate of heating networks and the planning of pipe replacement in an automated control system for the heating networks operation, Heat Supply News, 11 (2014)

9. V.I. Matveyev, Experience in the diagnosis of heating networks at the Municipal Unitary Enterprise Yoshkar-Ola TPP-1, Heat Supply News, 7(11), 24-27 (2001)

10. G.A. Bigus, A.B. Schastlivtsev, M.A. Sabrekov, Acoustic emission control on pipelines of the main heating networks of the Norilsk industrial region, Heat Supply News, 11(195) (2016)

11. Sh.G. Ganshin, Yu.V. Vankov, E.V. Izmaylova, Monitoring the technical condition of pipelines by acoustic methods, 160 (2015)

12. T.G. Gorbunova, Yu.V. Vankov, T.O. Politova, Calculation and evaluation of the reliability index in the designing heating networks [Electronic resource], Engineering Bulletin of Don, 1 (2014) http://ivdon.ru/magazine/archive/n1y2014/2228 Russian language

13. A.M. Geroyeva, I.Yu. Zilberova, Forecasting and diagnostics of the technical condition of the municipal infrastructure facilities [Electronic resource], Engineering Bulletin of Don, 4 (2012) http://www.ivdon.ru/magazine/archive/n4p1y2012/ 1074 (free access) - Title from the screen. - Russian language

14. Gorbunova $\mathrm{T} G \mathrm{G}$ Vankov $\mathrm{Yu} V$ Politova $\mathrm{T} O$ Ziganshin Sh G Zagidullin D N 2013 Practical application of reliability index in designing heating networks [Electronic resource] Prescopus Russia: Open journal

15. Filimonov A V. 2009 Leak detectors for the searching leaks on the heating networks. // Heat Supply News, 5 